\title{
CD19-targeted chimeric antigen receptor-modified T cells induce remission in patients with relapsed acute B lymphoblastic leukemia after umbilical cord blood transplantation
}

\author{
Qianwen Xu${ }^{1}$, Hui Xu ${ }^{2}$, Lei Xue ${ }^{2}$, Min Wang ${ }^{3}$, Guifang Pan $^{3}$, Xuhan Zhang ${ }^{2}$, Kaidi Song ${ }^{2}$, \\ Wen $\mathrm{Yao}^{2}$, Xiang $\mathrm{Wan}^{2}$, Juan Tong ${ }^{2}$, Huilan Liu ${ }^{2}$, Hanying Xu ${ }^{3}$, Xin Liu ${ }^{2}$, Xiao-yu Zhu ${ }^{2}$, \\ Zi-min Sun $^{2}$, Lin Yang ${ }^{3}$, and Xing-bing Wang ${ }^{1}$ \\ ${ }^{1}$ Anhui Medical University \\ ${ }^{2}$ The First Affiliated Hospital of USTC \\ ${ }^{3}$ PersonGen-Anke Cellular Therapeutics Co., Ltd.
}

November 9, 2020

\begin{abstract}
Background Few therapies are available for treating patients with B acute lymphoblastic leukemia (B-ALL) who relapse after umbilical cord blood transplant (UCBT). Chimeric antigen receptor (CAR)-modified T cell therapy targeting CD19 is novel and effective for treating refractory/relapsed $(\mathrm{R} / \mathrm{R})$ hematological malignancies. Method We report the response rate, toxicity, and survival of CD19-targeted CAR modified T cells administered to 10 patients with B-ALL who relapsed after UCBT from April 2018 to September 2019. Patients [?]14 years of age were subsequently recruited in the clinical trial (NCT02851589) conducted at the First Affiliated Hospital of USTC, Hefei, China. Results Patients $(\mathrm{n}=11)$ were infused with peripheral blood $\mathrm{T}$ cells transduced with CD19-directed CAR lentiviral vectors $(0.42 \times 106-3.91 \times 106$ cells $/ \mathrm{kg}$ body weight $)$. Among 10 patients who were successfully infused, 9 achieved minimal residual disease-negative complete remission (MRD-neg CR). As of July 30, 2020, 6 of 10 patients experienced a relapse (median follow-up for CR was 13.2 months, range 5.8-31.7 months). The 6 -month rates of progression-free survival (PFS) and overall survival (OS) were $44.4 \%$ and $77.8 \%$, respectively. Toxicities were reversible, including severe cytokine release syndrome (CRS) ([?] grade 3) and neurotoxicity in 10\% (1/10) and 10\% (1/10) of patients, respectively, and no patient experienced graft-versus-host disease (GVHD). Conclusion CD19-targeted CAR-modified $\mathrm{T}$ cell therapy may therefore serve as a safe and effective approach for treating patients with relapsed B-ALL after UCBT. A multicenter clinical trial including more subjects is required to confirm safety and efficacy.
\end{abstract}

\section{Hosted file}

Manuscript.pdf available at https://authorea.com/users/374225/articles/491792-cd19-targetedchimeric-antigen-receptor-modified-t-cells-induce-remission-in-patients-with-relapsedacute-b-lymphoblastic-leukemia-after-umbilical-cord-blood-transplantation

\section{Hosted file}

Table.pdf available at https://authorea.com/users/374225/articles/491792-cd19-targetedchimeric-antigen-receptor-modified-t-cells-induce-remission-in-patients-with-relapsedacute-b-lymphoblastic-leukemia-after-umbilical-cord-blood-transplantation 


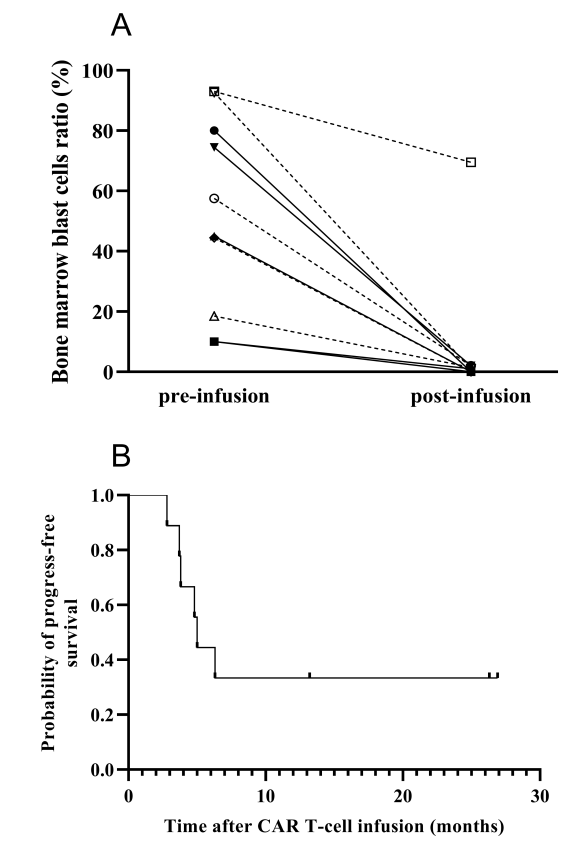

$$
\begin{array}{ll}
\rightarrow \text { Patient } 1 & \rightarrow-- \text { Patient } 6 \\
\rightarrow \text { - Patient } 2 & \rightarrow \text { Patient } 7 \\
\rightarrow-\text { Patient } 3 & \rightarrow-\cdot \text { Patient } 8 \\
\rightarrow-\text { Patient } 4 & \rightarrow \text { Patient } 9 \\
\leftarrow \text { Patient } 5 & \rightarrow \text { Patient } 11
\end{array}
$$
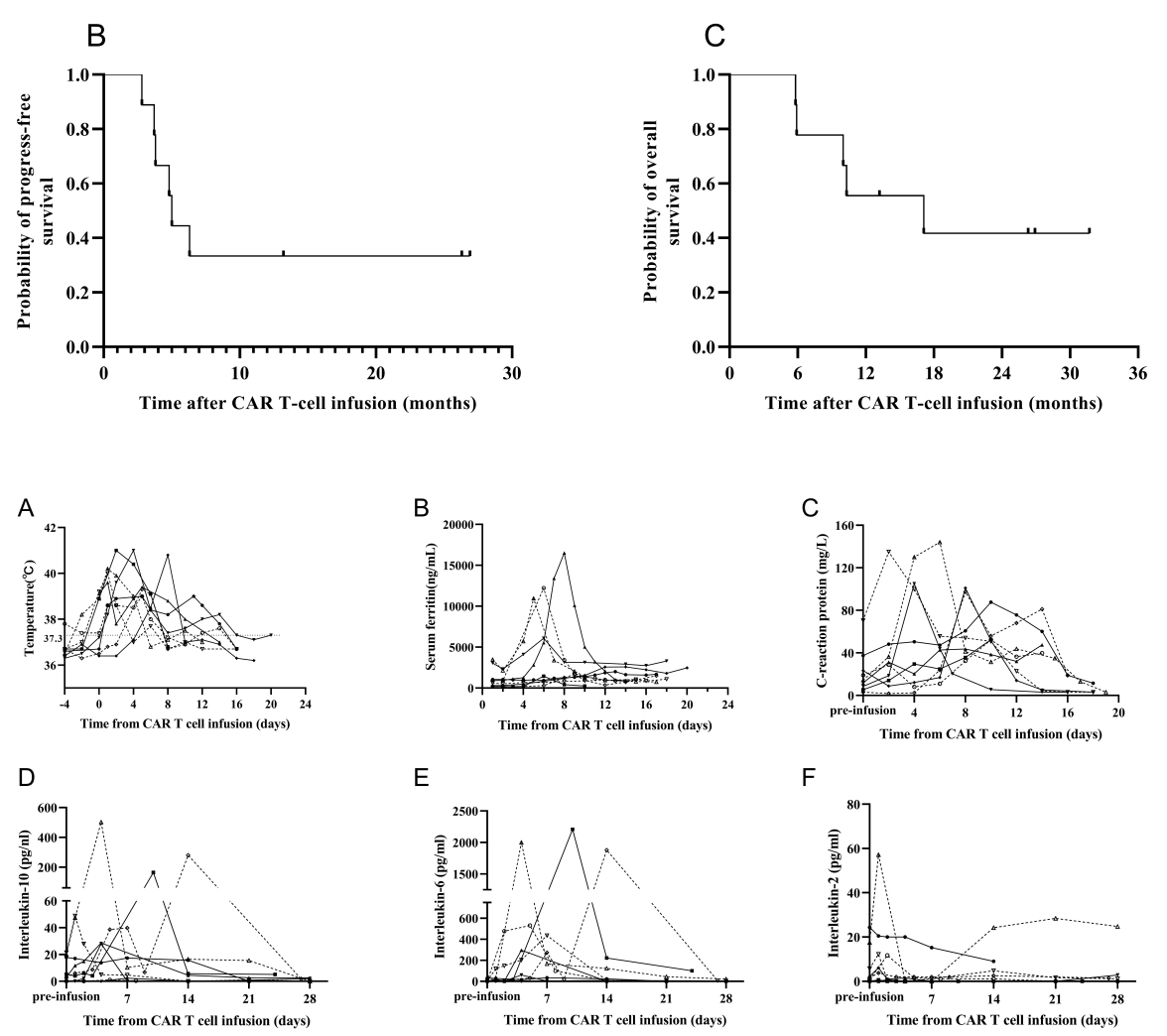

E

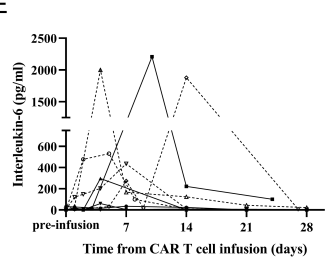

F
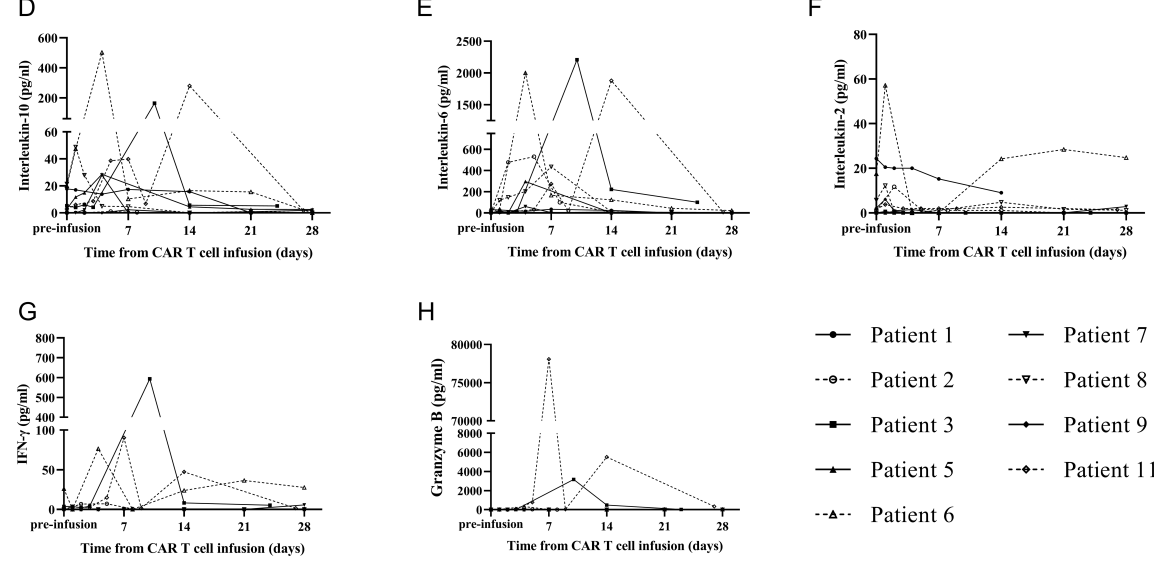

$$
\begin{array}{llll}
\rightarrow & \text { Patient } 1 & \rightarrow & \text { Patient } 7 \\
-\bullet-\cdot & \text { Patient } 2 & \rightarrow-- & \text { Patient } 8 \\
\rightarrow & \text { Patient } 3 & \rightarrow & \text { Patient } 9 \\
\rightarrow & \text { Patient } 5 & \rightarrow-- & \text { Patient } 11 \\
-\triangle-- & \text { Patient } 6 & &
\end{array}
$$



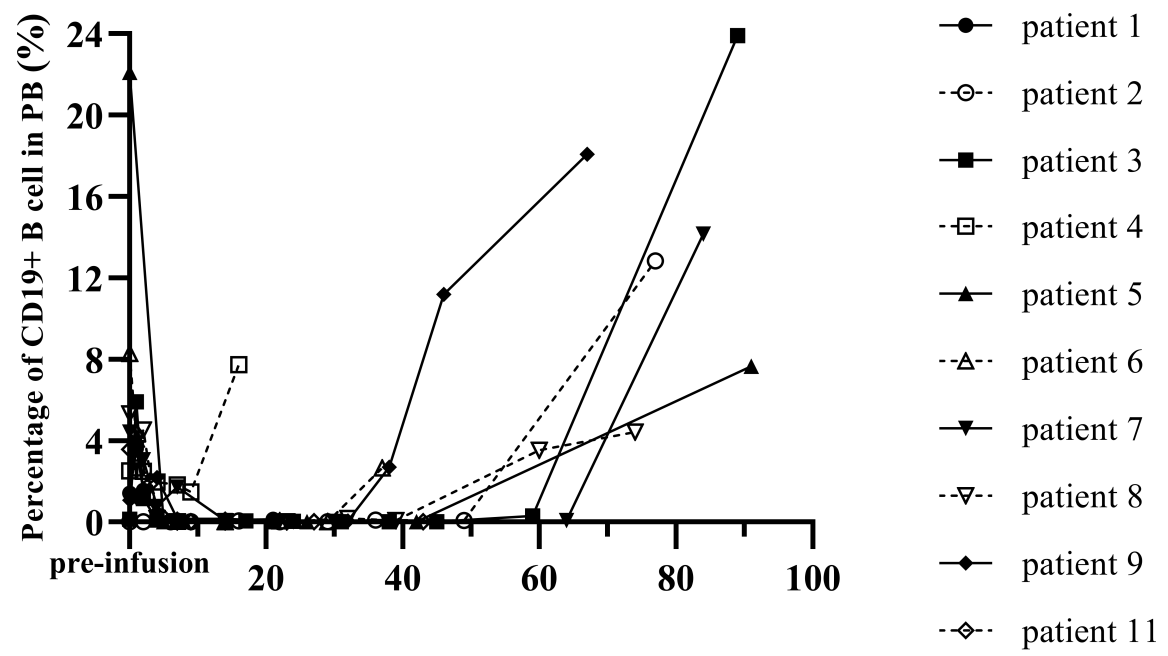

Time from CAR $\mathrm{T}$ cell infusion (days)

A

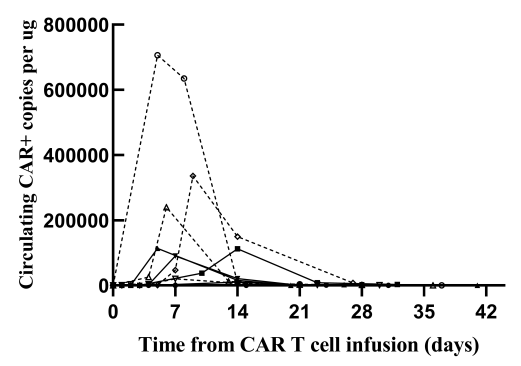

B

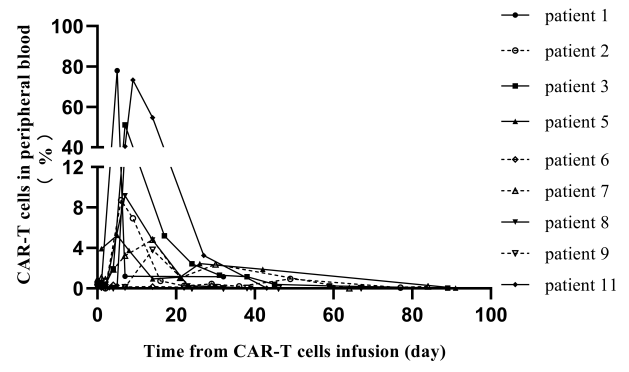

